\title{
EXCESSIVAMENTE HUMANO: O INOMINÁVEL MUNDO DOS DESEJOS
}

\section{Excessively Human: The unnamable World of the Desires}

\author{
Maria das Mercês Maia Muribeca ${ }^{1}$
}

\section{Resumo}

Somos seres milenares, porém, até os dias de hoje, buscamos compreender o que impulsiona o desejo humano a atuar. As emoções surgem da trama dos afetos, que, por sua vez, estão inseridos no labirinto mundo dos desejos. Não sabemos como nos deixamos ser invadidos pelos sentimentos, seduzidos pelo fascinante mundo das paixões, mas ironicamente somos seres em essência de puro desejo. Queríamos ter respostas concretas sobre o que somos e sentimos, mas a própria vida nos ensina que não somos senhores em nossa própria morada. Não somos os donos de nossas emoções, não damos conta do desejo inconsciente que move nossas paixões. Nesse sentido, reza o mito que o amor é cego e anda guiado pela loucura, diz a lenda que a paixão carregada de ciúmes leva à obsessão e, da obsessão, o encontro com o desvario é inevitável.

Palavras-chave: Desejos; Emoções; Paixão; Sentimentos.

\section{Abstract}

We are millenarian beings, however even now we seek to understand what stimulates the human desire. Emotions are caused by passion, and in turn they are inserted into the labyrinthine world of desires. We do not know how we let ourselves be invaded by feelings, seduced by the fascinating world passions. Ironically, we are the essence of pure desire.

We want to have concrete answers related to what we are and what we feel, but our lives teach that we are not masters of our own houses. We are not the owners of our emotions; we cannot control our unconscious desires that move our passions. This suggests the myth that love is blind and walks guided by madness. It suggests the legend that passion filled with jealousy leads to obsession, and that obsession leading to derangement is inevitable.

Keywords: Unconscious desires; Emotions; Passion; Feelings.

1 Psicóloga Clínica - Psicanalista - Membro da Sociedade Psicanalítica da Paraíba (SPP) - Membro do Círculo Brasileiro de Psicanálise. Doutora em Fundamentos y Desarrollos Psicoanalíticos - Universidad Autónoma de Madrid - España

End: R. Catulo da Paixão Cearense, 627/ 901. Jardim Luna - João Pessoa -PB. $\quad$ 58.033-060

E-mail: muribeca@openline.com.br 
"A psicanálise se interessa pelo ser humano como autor, como sujeito de seu discurso, o que o conduz a seu próprio fantasma, onde se articula seu desejo". (Tubert, 1991)

Passamos a vida tentando entender o fantástico mundo dos sentimentos, buscamos incessantemente encontrar algo que nos é desconhecido. Lutamos para entender qual é a verdadeira essência de nosso ser, tentamos colocar em palavras a experiência oculta que existe em nós, mas não sabemos como fazê-lo, o único que sabemos é que não podemos ficar com aquilo que vivemos, necessitamos passar adiante, transmitir para alguém algo de nós mesmos.

Hoje, em pleno século da linguagem, estamos preocupados em ler, decifrar e compreender todos os símbolos, signos e significantes que fundam nossa existência. As ciências humanas estão buscando encontrar esse saber, desenterrar esse enigma, fazer inteligível o que é ininteligível.

Assim vivemos como arqueólogos geração após geração, em busca de desentranhar peça por peça o mistério que caracteriza e encobre nossa existência e o que nela há de excessivamente humano.

Tentamos dar conta, mesmo que seja apenas em um lampejo, de saber um pouco mais acerca desse insondável e inebriante universo do coração do homem, representante por excelência dos sentimentos, o qual em essência ignoramos em sua íntegra. Como conhecer o interior deste enigmático mundo dos afetos, onde em toda sua exuberância, habita o desejo inconsciente que nos faz ser e sentir?

Blaise Pascal, (Citado por Chaiu, 1995) filósofo francês do séc. XVII, costumava dizer que: "O coração tem razões que a própria razão desconhece".

Portanto, pretender trabalhar a temática dos sentimentos é algo extremamente complexo, pois muitas vezes somos envolvidos na teia de aranha de nossas próprias paixões, de forma que elas parecem sempre intervir em nossos escritos, restos de nossas próprias centelhas de desejos inconscientes, fazendo assim que, na maioria das vezes, turbem-se nossas intenções de avanços.

Por isso, falar da trajetória do desejo, verdadeiro labirinto de sedução, em nossas vidas, não é tarefa fácil. Como entender seus conflitos, suas paixões, seus afetos, sua essência, tudo aquilo que não podemos nomear, pois vai além daquilo que nossos pensamentos possam expressar em palavras, e nosso cérebro possa elaborar em seus intricados sistemas de funcionamento.

Mas, mesmo assim, esse mesmo desejo nos inspira a falar da arte da sedução, do amor, do ciúme, da loucura, e de muitos outros sentimentos que compõem nossa trajetória de vida.

Desse modo, como diria Lacan (1988), todo sujeito se situa no campo do desejo, e como não podia deixar de ser, ele se move por aquilo que desconhece, de forma que existe uma grande relevância da fala na produção do objeto do desejo, que tanto causa como sustenta o desejo e, portanto, o que se busca na fala é a resposta do outro.

Sobre isso, Drummond de Andrade (Citado por Chaui, 1995), costumava dizer: “(...) Penetra surdamente no reino das palavras (...) Chega mais perto e contempla as palavras. Cada uma tem mil faces secretas sob a face neutra".

São as mil e uma faces de Eros, como assinalaria McDougall (1998), que nos seduz e abandona, sua mirada em nossa direção é profundamente: forte, enigmática, erótica, ilusória, incessante, insaciável, ambivalente, infinitamente penetrante, exuberante dialética do desejo em nós.

Shakespeare (2003), em Otelo, traduz brilhantemente a ambivalência do desejo quando disse: "Não me explico porque hoje amo e amanhã odeio".

O que Freud (1928), certamente, deixou bem marcado ao ressaltar: "Como são estranhas à nossa consciência as coisas pelas quais nossa vida mental inconsciente é governada!"

Assim o sujeito sente assombro diante de suas incongruências, temor ao desconhecido, medo do que vê quando está diante do espelho e do outro lado somente encontra a imagem do vazio, eco da desorganização caótica que circula nas mentes cansadas de buscar esse saber que não se sabe, da composição decomposta do ser. Ali do outro lado o outro foge, não existe nada certo ou errado, vida e morte nela se confundem e se instaura a solidão, marca registrada da ausência do outro. Esse outro que é peça fundamental de sua existência e que o induz a seguir buscando, por meio de seu próprio ser, encontrar a plenitude.

Nesse sentido, o homem sofre por querer o que não tem e, quando o consegue, sofre porque a satisfação do desejo é ilusória e efêmera. 
Schopenhauer (1994) costumava dizer que: "Querer é essencialmente sofrer e, como o viver é querer, toda a existência é essencialmente dor".

Assim, para ele, todo desejo nascia de uma necessidade, de uma privação, de um sofrimento. Deste modo, ele pôde afirmar que: "O homem não é nada mais que vontade, desejos encarnados, um composto de mil necessidades".

Shakespeare (2003), em Otelo, fazia seu protagonista dizer dolorosamente: "Não dou conta de minha vontade". Provavelmente esse seja um dos conflitos mais angustiantes do ser humano, obrigado a viver sem nada saber sobre seus desejos, vivendo a dualidade de seus sentimentos, num emaranhado de razão sem emoção e emoção sem razão, ele vai tecendo suas próprias ciladas. Assim, quase imperceptivelmente, essa trama dos afetos e essa ambivalência dos desejos torna-se parte da essência do humano.

Desde muito cedo, o ser humano aprende sobre a prioridade do outro adulto em sua vida, quando no ato mesmo do nascer já experimenta uma ruptura, uma cisão produzida no silêncio da angústia de separação, causando-lhe a estranha sensação de que algo lhe falta, algo que lhe era essencial e que foi perdido. E é atrás dessa falta básica que ele passará toda sua vida a buscar.

É certo que há uma perda na origem da vida, uma grande e inolvidável perda, da qual não podemos escapar, nomear, visualizar, nem tampouco definir ou contextualizar, o único que sabemos é que há uma perda em nós, a perda de algo que nos era vital e que foi deixado para trás, onde não podemos mais alcançar. Entretanto, como é possível sentir falta de algo que não conhecemos, que talvez nunca nos tenha pertencido?

Sabemos que desde o nascimento, começamos a trilhar caminhos decisivos com vistas à estruturação de nosso ser, muito cedo iniciamos um processo de autodescobrimento, uma busca que nos impulsiona ao desconhecido. Devagar, vamos percebendo que nosso ser começa a se revelar como uma ilha ainda virgem, cheia de mistérios e segredos a desvendar.

É assim que o ser humano torna-se um ser marcado pela falta, um ser que vive uma eterna busca como conseqüência do desejo de encontrar a plenitude e esse desejo leva-o a percorrer caminhos que vão sofrer a influência voraz de um desencontro. No entanto, a vida deveria ser a arte dos encontros, mas nossos desejos inconscientes, sempre comprometidos com a raiz da insatisfação que os caracteriza, impulsiona o sujeito a fazer um movimento, compulsivo e desenfreado dentro de uma cadeia de significantes, que por sua vez estão encobertos de misteriosos labirintos, que constantemente lhes está remetendo a um outro significante e assim sucessivamente.

Como tão bem diria Lispector (1988): “(...) estamos buscando, estamos buscando. Tentamos compreender. Tentamos dar a alguém o que vivemos e não sabemos a quem, mas não queremos ficar com o que vivemos. Não sabemos o que fazer com isso, temos medo dessa desorganização profunda."

Sabemos que nossos sentimentos bailam diante de nós e com eles muitas vezes caímos na emboscada dos afetos e, atordoados, tornamo-nos cativos de nós mesmos. Enredado pela ambivalência do desejo, o ser humano termina por ser prisioneiro de suas próprias armadilhas, não sabendo como se emaranhou, desconhece como alcançar a liberdade.

A luta para nos desvencilhar de um afeto que nos é penoso é ainda mais difícil quando ele permanece vivo em nós, entrelaçado na areia movediça, onde habita nossas emoções, desejo do nada, do tudo, espaço vazio do indizível, folha invisível da história, cilada das paixões articuladas na intenção de esconder a falta, desejo de voltar, retornar à essência de puro prazer, onde começa e termina toda a história da qual fazemos parte e partimos.

Devaneio, profundo devaneio, é o que nosso ser de autêntico desejo nos leva a dizer, a utilizar da palavra para dizer o que não somos, o que nunca fomos, o que pensamos que somos. Assim, por meio da linguagem, criamos mundos, fabricamos máscaras, inserimo-nos no teatro da vida, no universo mágico das representações, deixamos ver nossas máscaras, apenas não deixamos ver nossa face.

Sófocles (1987), em Édipo, disse: "Era cego frente a seu próprio desejo. Ele nada sabia”.

Esse ele nada sabia nos faz pensar que 0 desejo é um saber que o sujeito não pode aceder, portanto inconsciente; que o desejo é sempre o desejo do outro; e conseqüentemente o desejo permanece para sempre insatisfeito, o que leva a uma busca incessante de novos objetos, na tentativa de obter a satisfação tão almejada, mantém o sujeito num lugar de angústia, de ser castrado na manutenção de seu desejo. 
Na paixão o sujeito alimenta a ilusão de haver preenchido essa falta com um objeto amoroso, transformando toda escolha amorosa numa certa referência narcísica que coloca o amor numa área de ilusão, ao mesmo tempo imprescindível e essencial ao homem. $\mathrm{O}$ objeto de desejo nas relações passionais adquire a dimensão de um objeto não só de prazer, mas de necessidade no sentido de uma compulsividade.

O ser apaixonado vive no mundo da fantasia, e compulsivamente mantém a lenha dessa fogueira bem acesa. Preso no mundo das fantasias, necessárias para a manutenção desta ilusão, o sujeito se fecha cada vez mais nas entranhas de seu próprio ser, alheio aos acontecimentos do mundo lá fora. O ser apaixonado bebe do vinho da euforia e extasiado acredita que, a cada instante, coisas improváveis lhes vão acontecer e assim sonha com a realização do impossível. A ilusão transforma-se, então, no instrumento de que se serve 0 amor para tornar-se belo e imortal enquanto existir. Como tão bem dizia o poeta Vinicius de Moraes: "Que não seja imortal posto que é chama, mas que seja infinito enquanto dure".

No entanto, reza a lenda que a paixão carregada de ciúmes leva à obsessão, e da obsessão o encontro com o desvario é inevitável. Decerto, incerto, é certo a loucura e o ardor do desejo, sentimento profundo que nos faz perder a razão para viver a sem razão do ciúme, da posse, da exclusividade do ser desejado. Por isso, costumase dizer que a paixão é cega e anda guiada pela loucura, que no mundo dos sentimentos todos bailam cegos e loucos em algum momento buscando encontrar o brilho e a lucidez do olhar da sabedoria. Mas quando a intimidade entre os amantes está proibida e a paixão é um pecado, então, o amor é o delito mais atrevido de todos.

Dessa forma, o ser humano se abandona à experiência, ao contato com a coisa em si, com sua própria enfermidade, com sua exclusiva sanidade, descobre a matéria inorgânica da qual seu ser está constituído, desvanece, delira, enlouquece ao mesmo tempo em que se desnuda, mescla a essência, vida e morte se entrelaçam, cegueira e loucura traçam lucidez, volta ao silêncio, à origem, ao nada.

Clarice Lispector (1998) consegue traduzir tão bem isso quando disse: "Margarida a Viole- ta conhecia, uma era cega, uma bem louca vivia, a cega sabia o que a louca dizia; e terminou vendo o que ninguém mais via".

Sonho, ilusão, devaneio, ai está o desejo, no meio, no nada, no que foi dito, no que não pode ser dito, no nunca dito. Paixão sem limite, eterno desejo de ter o outro sob domínio, desejo do outro que nada mais é que o próprio ser que habita nas entranhas insondáveis do seu ser desconhecido, que se cria e se recria no outro.

A vida, então, vai se constituindo numa sucessão de sucessos e insucessos que se sucedem sucessivamente durante os séculos traduzidos em tempos que se alternam constantemente em momentos de felicidade e de tristeza, mas mesmo nessa dialética dos sentimentos, encontramos que esses momentos são sempre carregados de afetividades que vão construindo e estruturando a nossa história.

Como tão bem dizia Henry James (Citado por Tubert, 1988): “O homem é a soma de suas fantasias".

Assim, somos marcados por lembranças que nos levam a navegar em várias imagens do que um dia nos apropriamos como nossa, lugares, pessoas, tempo que não volta jamais, mas que juntos um a um formam o que hoje entendemos como sendo o autêntico percurso da história do desejo em nossas vidas.

A verdade de nossos desejos é a mentira do espelho, e o espelho é a verdade das nossas mentiras. Então, a verdade possui uma estrutura, por assim dizer, de ficção. Verdade e mentira se entrecruzam num campo onde já não se distinguem mais, são linhas muito frágeis que separam a verdade da mentira, mas é por meio e em nome dessa verdade que o sujeito conduz sua investigação, verdade em si que o coloca em uma busca desenfreada da essência que constitui a matéria da qual seu ser é composto.

Talvez a maior complexidade da vida seja encontrar a verdadeira identidade que o nosso ser possui. Saber ser e estar em si e no mundo ao mesmo tempo, quiçá seja uma das empreitadas mais difíceis que o ser humano possa travar consigo mesmo.

Dessa forma, o sujeito está determinado por um saber do qual ele mesmo desconhece, ele desconhece seu próprio desejo, mas ele pode ex-

\footnotetext{
${ }^{2}$ Soneto da fidelidade.
} 
trair a força do desejo das palavras, não da palavra propriamente dita, mas da palavra disfarçada, porque a verdade do desejo jamais dá a face, ela sempre surge embaixo de um disfarce, sendo desejos ocultos a ele mesmo, o propulsor do seu ser, esse ser que lhe é tão estranho-familiar.

Assim, concordamos com Marilena Chauí (1995) quando disse que: "A palavra tem esse poder misterioso de transformar o que não existe em realidade e de dar a aparência de irrealidade ao que realmente existe".

Afinal, somos seres milenares, seres em essência de puro desejo e necessitamos nos sentir livres para não sermos prisioneiros de nós mesmos.

Queríamos ter respostas concretas sobre o que sentimos e por que sentimos, mas a própria vida nos ensina que não somos senhores em nossa própria morada, não somos donos de nossas próprias emoções, não damos conta do desejo inconsciente que inspira nossas paixões e que são traduzidos em atitudes carregadas de mensagens enigmáticas, como diria Laplanche (1988), e que ao final nos leva de volta às origens.

O certo seria se pudéssemos viver nossas emoções e sentimentos de uma forma ao mesmo tempo arrebatadora e serena, sem transformá-los em propulsores de angústia, geradores dos confli- tos da alma, mas propiciando aos enamorados uma forma de esquivar-se dessa inebriante armadilha do desejo ao qual se fez prisioneiro, abrindo mão da fantasia idealizadora que adapta estas escolhas, possibilitando a união com o outro na sua alteridade, podendo vislumbrar em meio a essas diferenças novas possibilidades de descobrir e redescobrir o outro em sua essência.

Assim, seguimos nossa eterna busca em prol do saber que não se sabe. Empreendemos uma busca inesgotável a fim de achar respostas que possam acalmar nossas angústias, e quando pensamos haver encontrado tais respostas às nossas perguntas, seguimos insatisfeitos e desejamos, uma vez mais, seguir investigando até obter uma solução ainda mais precisa para nossas indagações, mesmo que todo saber não passe de uma mera ilusão de um saber, todavia maior, que oculta 0 verdadeiro saber que, um mesmo, nunca logre saber.

Gostaria de finalizar com uma frase de Alcocer (1993), que considero iluminada, quando afirma:

“(...) ainda que o código genético fique definido a perfeição, nunca dará conta do desejo que une, ou reúne, ou desune, aos seres humanos". 


\section{Referências}

Alcocer, M. C. (1993). Revista fundamentos teóricosy práctica clínica: Diversos Enfoques. Monografies del Col.legi Oficial de Psicòlegs del País de Valencia.

Bulfinchi, T. (2001). O livro de ouro da mitologia: Histórias de deuses e heróis (15a ed). Rio de Janeiro: Grupo Ediouro.

Chaui, M. (1995). Convite à filosofia. São Paulo: Ática.

Freud, S. (1928 [1927]). Dostoievski e o parricídio. (Vol. XXI, ESB). Rio de Janeiro: Imago.

Lacan, J. (1988). Escritos 1. Argentina: Siglo XXI.

Laplanche, J. (1988). Teoria da sedução generalizada e outros ensaios. Porto Alegre: Artes Médicas.

(1992). La prioridad del otro en psicoanálisis. B. Aires, Amorrortu.
Lispector, C. (1988). A paixão segundo G. H. Rio de Janeiro: J. Olympio.

(1998). Perto do Coração Selvagem. Rio de Janeiro: Rocco.

Mucida, A.M.S. (1988/1989). Revista de Filosofia: Kriterion. B. Horizonte. 31 (8I-82),.

Nágera, J. A. V. (1998). Guía práctica de psicología. Madrid: Vivir mejor.

Schpenhauer, A. (1994), Dores do Mundo: C. (Clássicos de Bolso). [S.l.]: Ediouro.

Shakespeare, W. (2003), Otelo: O Mouro de Veneza. [S.l.]: Martin Claret.

Sófocles (1987). Tragedias completas. Madrid: Alba.

Tubert, S. (1988). La sexualidad femenina y su construcción imaginaria. Madrid: El Arquero.

(1991). Mujeres sin Sombras, maternidad y tecnología. Madrid: Siglo XXI. 